\title{
Decreased Expression of Genes Associated with Memory and X-Linked Mental Retardation in Boys with Non-Syndromic Cryptorchidism and High Infertility Risk
}

\author{
F. Hadziselimovic a N.O. Hadziselimovic ${ }^{a}$ b P. Demougin ${ }^{c}$ E.J. Oakeley ${ }^{d}$ \\ ${ }^{a}$ Institute of Andrology, Liestal, b Division of Molecular Neuroscience, Department of Psychology, University of Basel, \\ 'Department of Molecular Biology, Biozentrum, and d Department of Molecular Biology, Novartis Institutes for \\ Biomedical Research, Basel, Switzerland
}

\section{Key Words}

Cryptorchidism · Gene expression · Infertility · Memory ·

Mental retardation $\cdot$ Mini-puberty

\begin{abstract}
An elevated odds ratio for low IQ has been found for cryptorchid boys. Furthermore, poor school performance has been observed in cryptorchid boys with impaired mini-puberty. Gene expression analysis, qPCR and immunohistology were performed on testicular biopsies from 7 boys who underwent orchiopexy and had testicular histology typical of a high risk of infertility (HIR). The results were compared with 12 biopsies from cryptorchid boys with a low risk for developing infertility. The following genes associated with mental retardation were identically expressed: GDI1, OPHN1, PAK3, ARHGEF6, IL1RAPL, ACSL4, MECP2, RPS6KA3, ARX, and ATRX. However, boys in the HIR group had low or no expression of EGR4, FMR2 (AFF2) and VCX3A. In conclusion, impaired expression of genes known to encode proteins involved in signaling pathways that regulate cytoskeletal organization, synaptic vesicle transport and the establishment of connections between neuronal cells may contribute to reduced intellectual and cognitive functioning in infertile cryptorchid males.
\end{abstract}

(c) 2014 S. Karger AG, Basel

\section{KARGER}

() 2014 S. Karger AG, Basel

1661-8769/14/0052-0076\$39.50/0

E-Mail karger@karger.com

www.karger.com/msy
Undescended testes (cryptorchidism) is the most common genitourinary disorder of childhood and leads to 27,000 surgeries each year in the United States [Trussell and Lee, 2004]. The hallmark of successful treatment of cryptorchid boys is fertility. Whole-genome expression profiling shows that boys placed in the high infertility risk (HIR) group in accordance with their testicular histology have decreased or no expression of most of the genes essential for hypothalamic-pituitary-testicular axis function relative to boys with a low risk of infertility (LIR). In particular, EGR4, which is involved in regulating the secretion of luteinizing hormone, is virtually not expressed [Hadziselimovic et al., 2009]. Thus, EGR4 appears to be a master gene for fertility development [Hadziselimovic et al., 2009]. Further important functions for EGR4 have been identified; for example, EGR4 is involved in receptor-modulated memory processes [Li et al., 2005]. The previously described impaired expression of EGR4 would thus support Depue's [1988] observation of an elevated odds ratio for low IQ in boys with cryptorchidism. Here, we investigated the expression of genes associated with non-syndromic mental retardation and formation of long-term memory in cryptorchid boys with HIR versus LIR. 
Table 1. Primers used for PCR

\begin{tabular}{lll}
\hline Genes & Forward primer & Reverse primer \\
\hline TFRC1 & TCGTCCCTGCATTTAAAGGCTTTC & CAACAGTGGGCTGGCAGAAAC \\
GAPDH & GATCATCAGCAATGCCTCCTG & GAGTCCTTCCACGATACCAAAG \\
EGR 4 & AGCAAGAGATGGGTTTATG & AGGAGTTGGAAGAAGAGC \\
DLX2 & TTAGGTGCCTTTGCGGATGAC & ACAAACTCTGTGTCCAAGTCCAG \\
DDX25 & AGAATGTCTCAGTGGGTTTTG & GCTTCACATCAATTTGGCTTC \\
$M A G E A 4$ & GGCCAGTGCATCTAACAG & AAATAGAAACCCACTACTAAGAAC \\
\hline
\end{tabular}

\section{Methods}

Testicular Biopsies and Pooling of Patients

At our institution, it is routine practice to perform a testicular biopsy during surgery for undescended testes. We have found that testicular biopsies provide useful information about the quality of semen in the future and help to identify patients with atypical spermatogonia or carcinoma in situ. Cryptorchid testis is defined as a testis localized outside the scrotum and unable to be brought into a stable scrotal position. Nineteen rice-grain-sized testicular biopsies were analyzed, 7 from boys with impaired mini-puberty and HIR and 12 from boys with LIR. The age of the patients was comparable: HIR, mean 2.9 years (95\% CI 0.5-5.84); LIR, mean 3.6 years (95\% CI 2.78-4.41). Biopsies were fixed in 3\% glutaraldehyde and embedded in Epon. Semi-thin 1- $\mu$ m-thick sections were examined by Zeiss Axioscope phase contrast and conventional light microscopy (Plan-Apochromat $63 \times / 1.40$ oil). The methods for whole-genome analysis of testicular biopsies by Affymetrix microarrays were published in detail in our previous work [Hadziselimovic et al., 2009].

\section{Statistical Analysis}

The data analysis and gene filtering were performed using R/ Bioconductor [Gentleman et al., 2004]. Signal condensation was performed using only the RMA from the Bioconductor Affypackage. Differentially expressed genes were identified using the empirical Bayes method (F-test) implemented in the LIMMA package and adjusted with the False Discovery Rate (FDR) method [Wettenhall and Smyth, 2004]. We selected those probe sets with a log2 average contrast signal of at least 5 , an adjusted $p$ value $<0.05$ and an absolute log2-fold change of $>0.585$ ( 1.5 -fold in linear space). Hierarchical clustering and visualization were performed in $\mathrm{R}$.

\section{Quantitative Real-Time PCR}

Quantitative real-time PCR (qRT-PCR) was performed using a Corbett Research RG-6000 instrument. cDNAs were synthesized with the Reverse Transcriptase Core Kit (Eurogentec) using random primers (table 1). Real-time PCR runs were performed using the SYBR FAST Kit (Kapa Biosystems) with each gene-specific primer at $200 \mathrm{nM}$ final concentration in a total volume of $17.5 \mu \mathrm{l}$. Wave lengths of source and detection were set at $470 \mathrm{~nm}$ and 510 $\mathrm{nm}$, respectively. Gain was set at 8.33 . The PCR program was set as follows: $95^{\circ} \mathrm{C}, 60 \mathrm{~s} ; 45$ cycles $95^{\circ} \mathrm{C}, 3 \mathrm{~s} ; 60^{\circ} \mathrm{C}, 10 \mathrm{~s} ; 72^{\circ} \mathrm{C}, 4 \mathrm{~s}$; followed by a melting curve analysis $\left(65^{\circ} \mathrm{C}\right.$ to $95^{\circ} \mathrm{C}$, rising each step by $0.65^{\circ} \mathrm{C}$ ) to attest amplification specificity. Threshold cycles (crossing point) were determined using Rotor-Gene software ver- sion 6.1. Good PCR efficiency was checked by performing a dilution series of the cDNA.

Controls without reverse transcriptase were performed for each sample studied. Again, threshold cycles (crossing point) were determined using Rotor-Gene software version 6.1. Expression levels were normalized to TFRC1 and GAPDH using a geometric mean of their level of expression. Those genes were selected because they showed minimum variation between individual samples (both on microarrays and by qPCR). Fold differences were calculated using the $\Delta \Delta \mathrm{Ct}$ method (fig. 1).

\section{Antibody Validation}

For immunohistochemical analysis, the Epon was removed from the tissue sections. Sections were treated with $2 \%$ bovine serum albumin to reduce nonspecific binding and then incubated with the primary antibody overnight at $4^{\circ} \mathrm{C}$. All samples were washed with PBS between incubations. We validated 8 antibodies, along with EGR4, as described previously [Hadziselimovic et al., 2009].

\section{Ethical Considerations and Approval}

In accordance with the Declaration of Helsinki, the Institutional Review Board and the Independent Ethics Committee of the Children's Clinic in Liestal approved all aspects of this study. Approval was provided for research involving the use of material (data records or biopsy specimens) that had been collected for non-research purposes.

\section{Results}

Total RNA and cRNA samples were of high quality, the signal intensity distributions were similar and were within the normal range. As expected, overall signal intensities visualized using a distance matrix appointed HIR and LIR to separate groups. Of all transcripts overlapping the 2 groups, 378 were differentially expressed in HIR and LIR testes after statistical filtering. This gene list comprised 8 elevated and 370 decreased transcripts in HIR testes. The 20 genes identified from Affymetrix microarrays that showed the greatest differential expression between HIR and LIR and the highest significant differ- 
Fig. 1. Correlation of microarray data with data obtained by qRT-PCR on 4 genes that displayed significant expression changes, showing a high correlation in the obtained transcriptional profiles. The $y$-axis is the $\mathrm{Z}$ normalized $\log 2$ expression (array) and 2-normalized QT value (qPCR). Numbers on the $\mathrm{x}$-axis correspond to biopsy ID numbers. From Hadziselimovic et al. [2009].

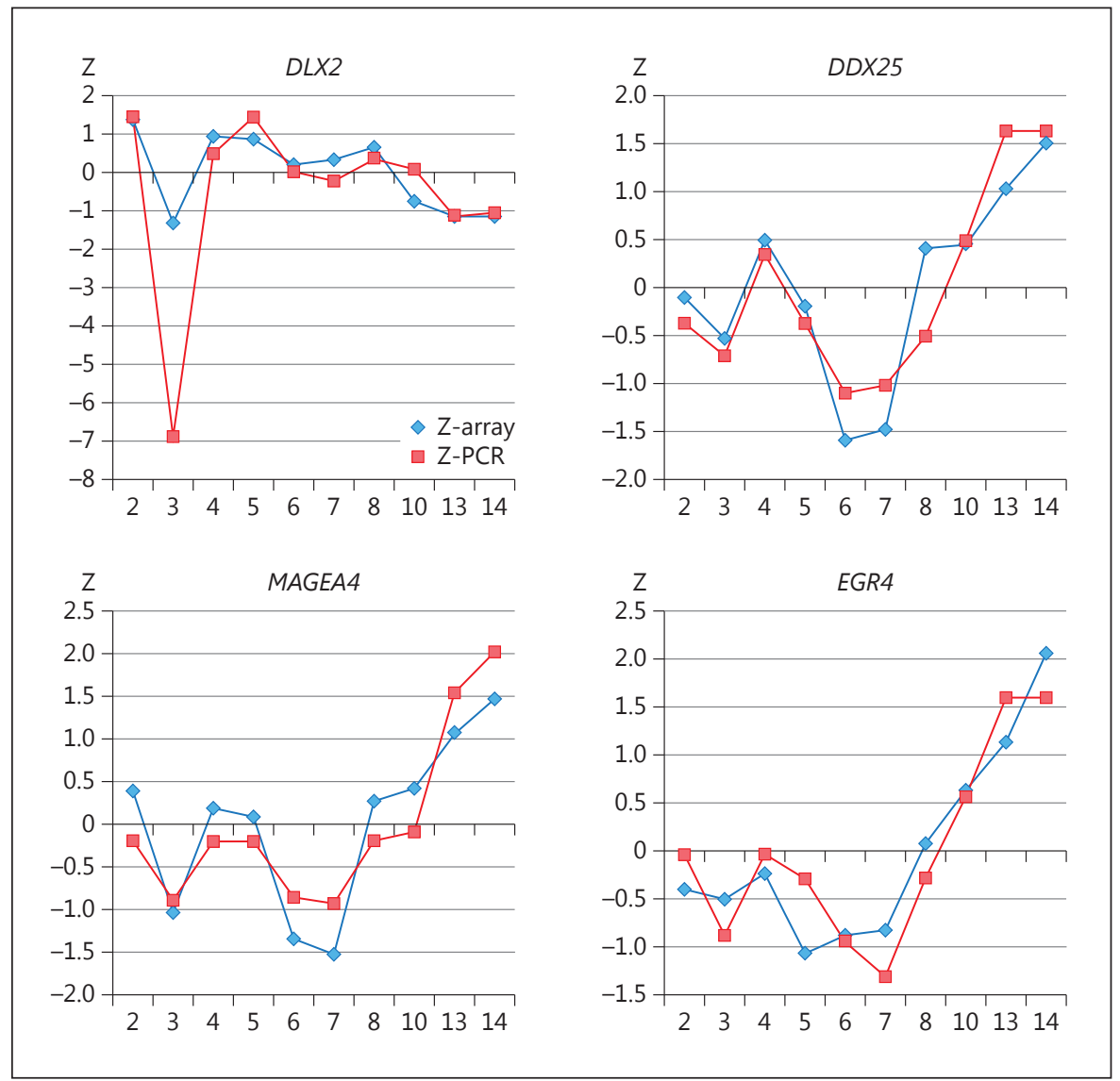

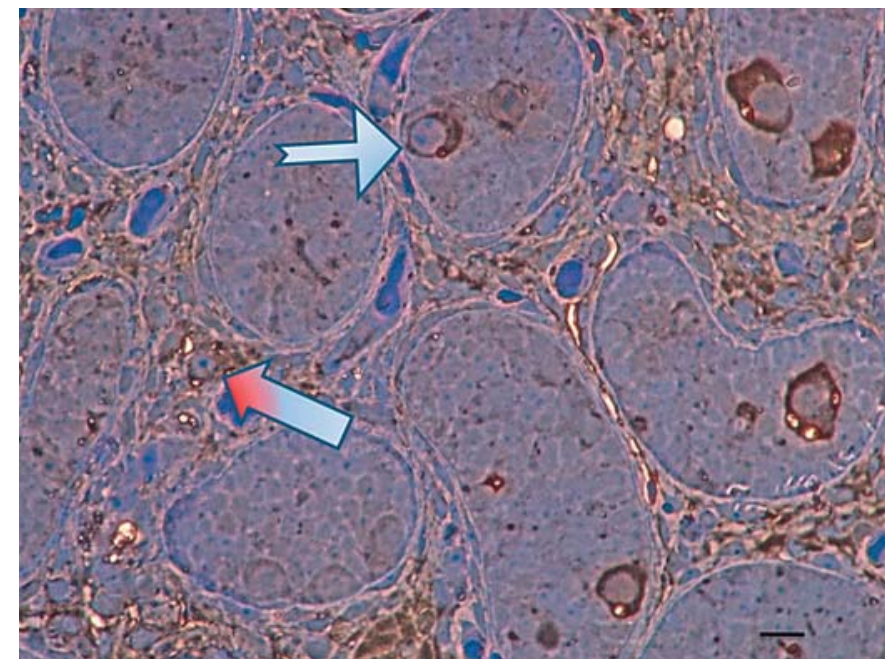

Fig. 2. Immunohistochemical staining of EGR4 in testes of the LIR group showing EGR4 localized in the cytoplasm of Leydig and germ cells (arrows). Contrast staining with toluidine blue. Scale bar $=0.1 \mathrm{~mm}$. From Hadziselimovic et al. [2009].

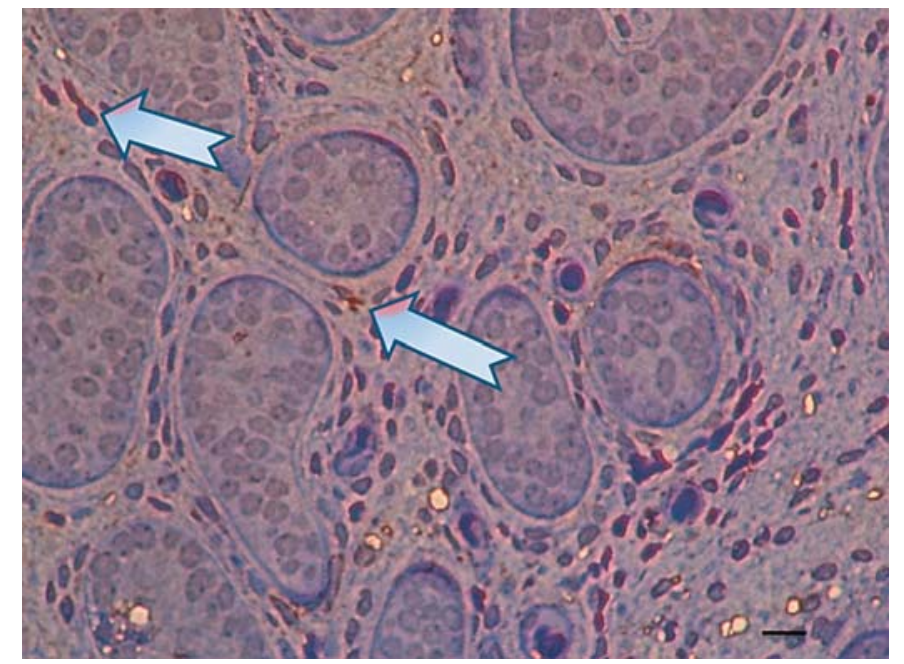

Fig. 3. Immunohistochemical validation of EGR4 in the HIR group. Atrophic Leydig cell cytoplasm was stained brown (arrows). We observed decreased EGR4 expression in degenerating spermatogonia. Contrast staining with toluidine blue. Scale bar = $0.1 \mathrm{~mm}$. From Hadziselimovic et al. [2009]. 
Table 2. The 20 genes showing the greatest differential expression between HIR and LIR

\begin{tabular}{|c|c|c|}
\hline Gene & $\begin{array}{l}\text { Adjusted } \\
\text { p value }\end{array}$ & Gene name \\
\hline TPTE & $8.70 \mathrm{E}-0.5$ & $\begin{array}{l}\text { transmembrane phosphatase with } \\
\text { tension homology }\end{array}$ \\
\hline ESX1 & $8.63 \mathrm{E}-0.5$ & ESX homeobox 1 \\
\hline MAGEC1 & $8.24 \mathrm{E}-0.5$ & melanoma antigen family $\mathrm{C} 1$ \\
\hline LOC722137 & $8.24 \mathrm{E}-0.5$ & \\
\hline TKTL1 & $8.24 \mathrm{E}-0.5$ & transketolase-like 1 \\
\hline HEY1 & $8.24 \mathrm{E}-0.5$ & $\begin{array}{l}\text { hes-related family bHLH transcription } \\
\text { factor with YRPW motif } 1\end{array}$ \\
\hline$D D X 4$ & $8.24 \mathrm{E}-0.5$ & DEAD box polypeptide 4 \\
\hline STK31 & $8.24 \mathrm{E}-0.5$ & serine/threonine kinase 31 (TDRD8) \\
\hline CPEB1 & $8.24 \mathrm{E}-0.5$ & $\begin{array}{l}\text { cytoplasmic polyadenylation element } \\
\text { binding protein } 1\end{array}$ \\
\hline FOXG1 & $1.21 \mathrm{E}-0.5$ & forkhead box G1 \\
\hline ELAVL2 & 0.00011 & $\begin{array}{l}\text { ELAV like neuron-specific RNA } \\
\text { binding protein } 2\end{array}$ \\
\hline MAEL & 0.00017 & $\begin{array}{l}\text { maelstrom spermatogenic transposon } \\
\text { silencer }\end{array}$ \\
\hline BEND4 & 0.00017 & BEN domain containing 4 \\
\hline TTK & 0.00017 & TTK protein kinase \\
\hline HMGA1 & 0.00017 & high mobility group AT-hook 1 \\
\hline PIWIL2 & 0.00017 & $\begin{array}{l}\text { piwi-like RNA-mediated gene } \\
\text { silencing } 2\end{array}$ \\
\hline RGMA & 0.00018 & $\begin{array}{l}\text { repulsive guidance molecule family } \\
\text { member a }\end{array}$ \\
\hline GTSF1 & 0.00019 & gametocyte specific factor 1 \\
\hline FGFR3 & 0.00019 & fibroblast growth factor receptor 3 \\
\hline$B A R D 1$ & 0.00019 & BRCA1 associated RING domain 1 \\
\hline
\end{tabular}

ence are presented in table 2 . The majority of the genes listed are dealing with spermatogenesis.

We found that the following genes, known to be involved in non-syndromic mental retardation, were equally expressed in the HIR versus LIR group of cryptorchid boys: GDI1, OPHN1, PAK3, ARHGEF6, IL1RAPL, and ACSL4. Furthermore, no differences in expression between the 2 groups of cryptorchid boys were observed for the genes MECP2, RPS6KA3, ARX, and ATRX, which are known to be involved in syndromic and nonspecific forms of mental retardation. In contrast, compared to the LIR group, the HIR group had low or no expression of EGR4, FMR2 (AFF2) and VCX3A (HIR vs. LIR; median values, $\log 2$ : $E G R 42.7$ vs. 5.65, p $<0.0006 ; F M R 24.71$ vs. $6.03, \mathrm{p}<0.003$; and $V C X 3 A 5.9$ vs. $7.46, \mathrm{p}<0.01)$.

To analyze tissue and organ gene expression, we included samples from patients diagnosed with undescended testes [Hadziselimovic et al., 2009] or from different human organs [Lardenois et al., 2010].

Decreased Expression of Memory Genes in Non-Syndromic Cryptorchidism
The tissue and organ gene expression profiles of the genes that we analyzed are known to vary considerably. GDI1, OPHN1, PAK3, ARHGEF6, ACSL4, MECP2, RPS6KA3, ARX, and ATRX are ubiquitously expressed in most human organs, while EGR4 is exclusively expressed in testis and brain tissue. VCX $3 A$ is expressed in brain, testis and salivary gland tissue, while FMR2 expression is specific to the testes. Finally, IL1RAPL is expressed only in the brain. In the current study, immunohistological analysis revealed lower EGR4 expression in the spermatogonia and Leydig cells of the HIR group compared to those of the LIR group (figs. 2, 3).

\section{Discussion}

Mental retardation is a symptom of many clinical conditions and affects around 3\% of the population [Nawarra et al., 2002]. Although the genetic causes of X-linked mental retardation are heterogeneous and complex, 8 genes involved in nonspecific X-linked mental retardation have been identified: FMR2, GDI1, OPHN1, PAK3, ARHGEF6, IL1RAPL, TM4SF2, and FACL4. Four other genes, MECP2, RSK2, $A R X$, and ATRX, are involved in syndromic and nonspecific forms of mental retardation [Nawarra et al., 2002]. We did not observe any differences between the HIR and LIR groups in the expression of most of the genes involved in mental retardation, except for FMR2. However, we found that the genes EGR4 and $V C X 3 A$ were virtually not expressed in the HIR group. Early growth response (EGR) transcription factors (EGR1 to EGR4) are synaptic activity-inducible immediate early genes that regulate some of the aspects of synaptic plasticity that are related to learning and memory. Long-term synaptic plasticity responses are long-lasting changes in the strength of synaptic connections, and they are believed to represent the cellular correlate of learning and memory [Lynch, 2004]. Previous studies have demonstrated that VCX-A is involved in nonspecific X-linked mental retardation [Fukami et al., 2000; Van Esch et al., 2005]. VCX-A is a non-canonical cap-binding protein that binds to capped RNA, but not to cap structures lacking bound RNA. Its cap association is enhanced by hDCP2, which further augments the ability of VCX-A to inhibit decapping. Thus, VCX-A can regulate mRNA stability and is an example of a tissue-specific decapping regulator [Jiao et al., 2006].

Nonspecific X-linked mental retardation is a clinically homogeneous but genetically heterogeneous entity. Apart from mental retardation, affected men in families segre- 
gating nonspecific X-linked mental retardation have no consistent phenotypic expression that distinguishes them from unaffected men or affected men in other families with X-linked mental retardation [Gecz et al., 1996]. Loss of FMR2 causes Fragile X E (FRAXE) site-associated intellectual disability [Melko et al., 2013].

In human organs, EGR4 is exclusively expressed in the testes and brain, while $V C X 3 A$, in addition to strong expression in the brain and testes, is also upregulated in the salivary gland. In humans and mice, the gene expression profiles of the brain, cerebellum and testes are more similar to each other than in other tissues [Guo et al., 2005]. Therefore, our finding of decreased expression of 3 genes in testicular biopsies, known to be involved in formation of long-term memory, adds additional support to the ob- servation of an elevated odds ratio for low IQ in cryptorchid boys. The Stanford-Binet test of intelligence was administered at age 4. IQ was considered low if $<70$ [Depue, 1988]. In addition, it may explain poor school performance in infertile cryptorchid men with impaired EGR4 expression [Hadziselimovic and Herzog, 1990].

In conclusion, we observed impaired expression of 3 memory genes known to encode proteins involved in signaling pathways that regulate cytoskeletal organization, synaptic vesicle transport and the establishment of connections between neuronal cells. This impaired expression may contribute to reduced intellectual and cognitive function in cryptorchid men. Thus, our findings may provide new insights into potential molecular mechanisms involved in the development of these functions.

\section{References}

Depue R: Cryptorchidism, an epidemiologic study with emphasis on the relationship to central nervous system dysfunction. Teratology 37:301-305 (1988)

-Fukami M, Kirsch S, Schiller S, Richter A, Benes $\mathrm{V}$, et al: A member of a gene family on Xp22.3, $V C X-A$, is deleted in patients with $\mathrm{X}$-linked nonspecific mental retardation. Am J Hum Genet 67:563-573 (2000).

-Gecz J, Gedeon AK, Sutherland GR, Mulley JC: Identification of the gene FMR2 associated with FRAXE mental retardation. Nat Genet 13:105-108 (1996).

-Gentleman RC, Carey VJ, Bates DM, Bolstad B, Dettling $\mathrm{M}$, et al: Bioconductor: open software development for computational biology and bioinformatics. Genome Biol 5:R80 (2004).

Guo JH, Huang Q, Studholme DJ, Wu CQ, Zhao Z: Transcriptomic analyses support the similarity of gene expression between brain and testis in human as well as mouse. Cytogenet Genome Res 111:107-109 (2005).
Hadziselimovic F, Herzog B: Hodenerkrankungen im Kindesalter (Hippokrates Verlag, Stuttgart 1990).

Hadziselimovic F, Hadziselimovic NO, Demougin P, Krey G, Hoecht B, Oakeley EJ: EGR4 is a master gene responsible for fertility in cryptorchidism. Sex Dev 3:253-263 (2009).

Jiao X, Wang Z, Kiledjian M: Identification of an mRNA-decapping regulator implicated in Xlinked mental retardation. Mol Cell 24:713722 (2006).

Lardenois A, Gattiker A, Collin O, Chalmel F, Primig M: GermOnline 4.0 is a genomics gateway for germline development, meiosis and the mitotic cell cycle. Database (Oxford) 2010:baq030 (2010).

Li L, Carter J, Gao X, Whitehead J, Tourtellotte WG: The neuroplasticity-associated Arc gene is a direct transcriptional target of early growth response (Egr) transcription factors. Mol Cell Biol 25:10286-10300 (2005).

Lynch MA: Long-term potentiation and memory. Physiol Rev 84:87-136 (2004)
Melko M, Nguyen LS, Shaw M, Jolly L, Bardoni B, Gecz J: Loss of FMR2 further emphasizes the link between deregulation of immediate early response genes FOS and JUN and intellectual disability. Hum Mol Genet 22:2984-2991 (2013).

Nawarra M, Bal J, Mazurzak T: Monogenic causes of nonspecific X-linked mental retardation molecular aspects. Med Wieku Rozwoj 6: 281-294 (2002).

Trussell JC, Lee PA: The relationship of cryptorchidism to fertility. Curr Urol Rep 5:142-148 (2004).

-Van Esch H, Hollanders K, Badisco L, Melotte C, Van Hummelen P, et al: Deletion of VCX-A due to NAHR plays a major role in the occurrence of mental retardation in patients with X-linked ichthyosis. Hum Mol Genet 14: 1795-1803 (2005)

Wettenhall JM, Smyth GK: limmaGUI: a graphical user interface for linear modeling of microarray data. Bioinformatics 20:3705-3706 (2004). 